\title{
The CNS-Specific Hyaluronan-binding Protein BEHAB Is Expressed in Ventricular Zones Coincident with Gliogenesis
}

\author{
Diane M. Jaworski, Gail M. Kelly, and Susan Hockfield \\ Yale University School of Medicine, Section of Neurobiology, New Haven, Connecticut 06510
}

\begin{abstract}
Hyaluronan (HA) is a ubiquitous component of extracellular matrices, and in several systems it plays a central role in regulating cellular proliferation and differentiation. Cell, or tissue,-specific functions of $\mathrm{HA}$ are likely to be mediated by cell, or tissue,-specific HA-binding proteins. We previously reported the cloning of BEHAB, a CNS-specific, secreted, hyaluronan-binding protein from rat and cat (Jaworski et al., 1994). In view of the potential role of HA in neural differentiation, we examined the expression of BEHAB during late embryonic and early postnatal development of the rat. BEHAB is expressed at very high levels in ventricular zones throughout the neuraxis. Expression is first detected at embryonic day 15 (E15) in the spinal cord, and is detected at progressively more rostral levels at later ages. BEHAB expression, llke other features of neural development, follows both caudal-to-rostral and ventral-to-dorsal gradients. The timing of BEHAB expression parallels the timing of the generation of glial cells. In all areas of the CNS examined, BEHAB expression begins after the peak of neurogenesis and coincident with gliogenesis. The regulation of proliferation and differentiation by HA in other tissues, together with the expression of BEHAB in zones of mitotic activity coincident with the generation of glia, suggests that the extracellular matrix protein encoded by BEHAB could play a role in the generation or differentiation of CNS glia.
\end{abstract}

[Key words: gliogenesis, development, hyaluronan, hyaluronan-binding protein, CNS specific, extracellular matrix]

A fundamental, but as yet unresolved, question in developmental neurobiology is how the apparently homogeneous population of cells in the neural tube neuroepithelium generates the cellular complexity and heterogeneity of the mature CNS. Two opposing mechanisms have been proposed. The first invokes the existence of committed progenitor cells within the ventricular zone, cach of which with the capacity to generate one, or a very restricted subset of, cell types (Levitt et al., 1981, 1983; LeVine and Goldman, 1988; Luskin et al., 1988, 1993). This mechanism dictates that intrinsic factors inherited by progeny are responsible for maintaining cell fate through development. The second proposes that the progenitor cells are multipotential,

\footnotetext{
Received May 26, 1994; revised Aug. 4, 1994; accepted Aug. 8, 1994.

We thank Dr. Michael Schwartz and the members of the Hockfield lab for many helpful discussions of this work. Support was provided by EY06511 (S.H.) and EY06451 (D.M.J.).

Correspondence should be addressed to Diane M. Jaworski, Yale University School of Medicine, Section of Neurobiology, 333 Cedar Street, SHM C-405, New Haven, CT 06510.

Copyright (c) 1995 Society for Neuroscience 0270-6474/95/151352-1 1\$05.00/0
}

with the capacity to give rise to many different cell types (Rakic, 1981; Turner and Cepko, 1987; Price and Thurlow, 1988; Galileo et al., 1990; Leber et al., 1990; Frank and Sanes, 1991; Williams et al., 1991). At the extreme, a single progenitor cell could give rise to the entire complement of neuronal and glial cell types (Turner and Cepko, 1987). The initial multipotentiality would be progressively restricted by a series of cell fate decisions regulated by environmental factors, through cell-cell and cell-matrix interactions. If intercellular cues determine fate choices, one would then expect to find cell surface or extracellular proteins localized to areas of cellular proliferation coincident with the generation of specific cell types.

In several tissues the extracellular matrix glycosaminoglycan hyaluronan (HA) and HA-binding proteins participate in the regulation of many aspects of cell proliferation, differentiation, and migration (Toole, 1991; Laurent and Fraser, 1992; Knudson and Knudson, 1993). In the brain, HA is expressed at highest levels in the embryo (Margolis et al., 1975; Delpech et al., 1989). Because HA is a ubiquitous component of extracellular matrices, any cell type-specific function for HA is likely to be mediated through tissue, or cell-, specific HA-binding proteins. Previously, we reported the cloning and initial characterization of BEHAB (brain enriched hyaluronan-binding protein), a secreted, CNS-specific, HA-binding protein (Jaworski et al., 1994). In the present study we report the temporal regulation and spatial distribution of BEHAB expression during the late embryonic period. The two major cell types in the CNS are generated over different time courses, with neurons largely generated in advance of glial cells (Altman, 1966; Das, 1979; Altman and Bayer, $1980 \mathrm{a}-\mathrm{c}$ ). The timing of BEHAB expression coincides with the generation of glial cells. BEHAB mRNA is abundantly expressed in the ventricular zone from embryonic day 16 to postnatal day 0 . BEHAB is the only CNS-specific HA-binding protein reported to date. This, combined with its enrichment in proliferative zones coincident with gliogenesis, suggests that BEHAB encodes an extracellular matrix protein that could play a role in glial cell generation or differentiation.

\section{Materials and Methods}

In situ hybridization was performed as previously described (Jaworski et al., 1994). Frozen sections $12-14 \mu \mathrm{m}$ thick were postfixed in phosphate-buffered $4 \%$ paraformaldehyde $(\mathrm{pH} 7.4)$, rinsed in $1 \times$ PBS, $2 \times$ SSC, and acetylated. Sections were then rinsed in $2 \times$ SSC, $1 \times$ PBS, dehydrated in ethanols, and delipidated in chloroform. Sections were prehybridized in $2 \times \mathrm{SSC}, 50 \%$ formamide at $50^{\circ} \mathrm{C}$ for $1 \mathrm{hr}$ and then hybridized in $0.75 \mathrm{M} \mathrm{NaCl}, 50 \%$ formamide, $1 \times$ Denhardt's, $10 \%$ dextran sulfate, $30 \mathrm{~mm}$ DTT, $10 \mathrm{~mm}$ Tris- $\mathrm{HCl}$ (pH 7.5), 1 mM EDTA, 100 $\mu \mathrm{g} / \mathrm{ml}$ salmon sperm DNA, $0.5 \mathrm{mg} / \mathrm{ml}$ yeast tRNA, and $1 \times 10^{6} \mathrm{cpm}$ ${ }^{3} \mathrm{~S}$-CTP-labeled probe per slide at $50^{\circ} \mathrm{C}$ for at least $12 \mathrm{hr}$. Following 

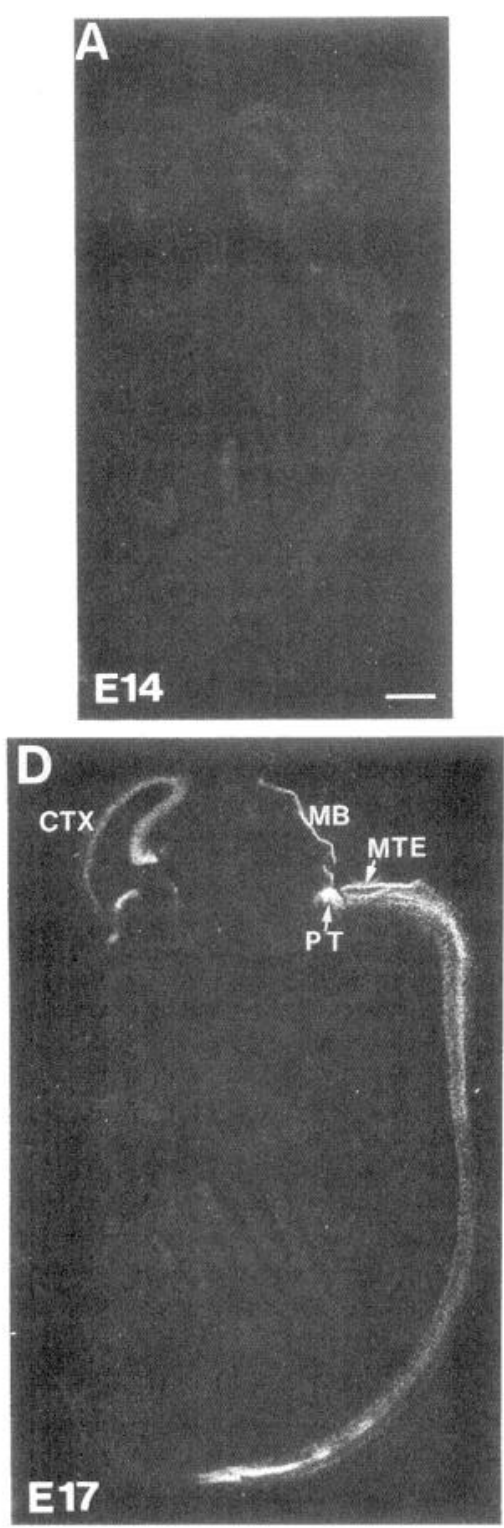
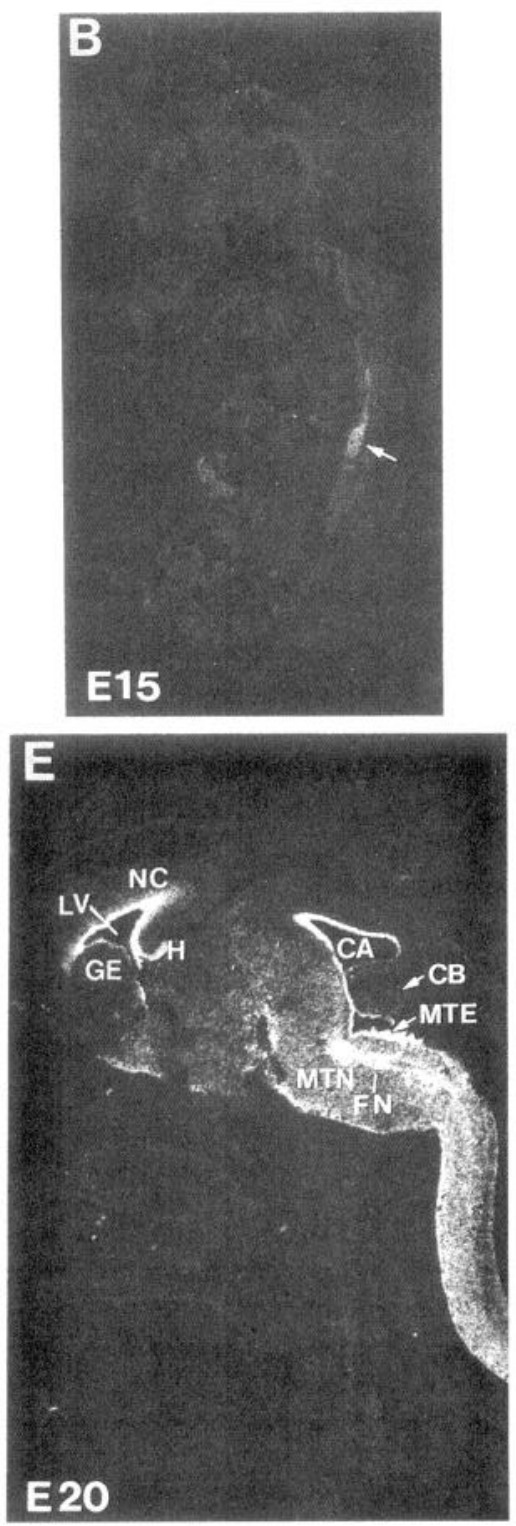
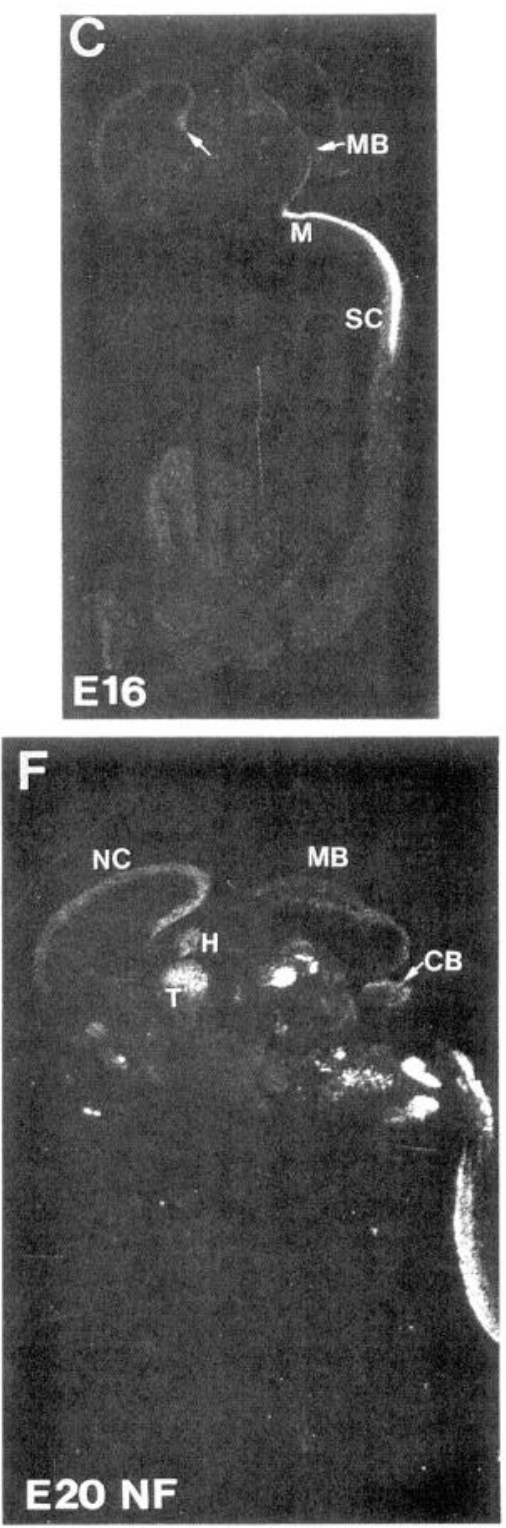

Figure 1. The distribution and developmental regulation of BEHAB mRNA in the embryonic nervous system. In situ hybridization was performed with a ${ }^{35} \mathrm{~S}$-labeled $\mathrm{cRNA}$ probe to BEHAB on parasagittal sections of rat embryos. $A$, BEHAB hybridization is not detected at embryonic day 14 (E14). B, At E15 only a small portion of the spinal cord displays detectable signal (arrow). $C$, At E16 an intense hybridization signal is present in the medulla $(M)$ and rostral spinal cord $(S C)$ extending through the zone of hybridization seen at E15. A less intense signal is present in the midbrain $(M B)$. A very faint signal is present in the most posterior ventral portion of the developing cortex (arrow). D, By E17 BEHAB is expressed over the entire rostrocaudal extent of the spinal cord. While BEHAB hybridization extends a greater distance from the ventricle in the spinal cord and medulla, the signal remains intense in the medullary tegmental neuroepithelium (MTE). BEHAB expression in the pons is most intense in the pontine tegmentum $(P T)$. In the midbrain $\mathrm{BEHAB}$ hybridization is increased from E16, but remains restricted to the ventral aspect of the ventricular zone. By E17 BEHAB is expressed throughout the developing cortical ventricular zone $(C T X)$. E, At E20 BEHAB hybridization is more intense in the neocortical ventricular zone $(N C)$ and hippocampus $(H)$. For the first time hybridization is detected in the ganglionic eminence $(G E)$, along the surface of the lateral ventricle $(L V)$. Unlike E17, hybridization in the midbrain is now detected along the dorsal surface of the cerebral aqueduct $(C A)$. In the brainstem, the motor trigeminal nucleus $(M T N)$ and facial nucleus $(F N)$ express BEHAB. The intense hybridization observed in the MTE at E17 is maintained at E20. In the spinal cord, BEHAB hybridization is enriched in the ventral gray, but also extends into the white matter. BEHAB is not expressed in the developing cerebellar primordium $(C B)$. $F$, As a positive control, a near adjacent section was probed with neurofilament-middle $(N F)$ at E20. NF displays a distinct hybridization pattern from that of BEHAB. Unlike BEHAB, NF is not restricted to the ventricular zone of the neocortex $(N C)$ or midbrain $(M B)$. Also, NF is expressed in the thalamus $(T)$ and cerebellar primordium. Scale bar, 1 mm.

hybridization, sections were washed in $2 \times$ SSC, $50 \%$ formamide, $0.1 \%$ BME ( $\beta$-mercaptoethanol) at $50^{\circ} \mathrm{C}$ for $1 \mathrm{hr}$ and treated with $20 \mu \mathrm{g} / \mathrm{ml}$ $\mathrm{RNase} A$ at $37^{\circ} \mathrm{C}$ for $30 \mathrm{~min}$. Sections were then washed in $2 \times \mathrm{SSC}$, $50 \%$ formamide, $0.1 \% \mathrm{BME}$ at $58^{\circ} \mathrm{C}$ for $30 \mathrm{~min}$ and $0.1 \times \mathrm{SSC}, 0.1 \%$ $\mathrm{BME}$ at $63^{\circ} \mathrm{C}$ for $30 \mathrm{~min}$ and dehydrated.

For initial localization of the probe, slides were exposed to film $(\mathrm{Hy}-$ perfilm, Amersham) for $4 \mathrm{~d}$. Autoradiograms were used as negatives for prints. Sections used for autoradiograms were counterstained with cresyl violet and projection printed directly onto photographic paper. For higher-resolution analysis of probe distribution, slides were dipped in NTB-2 emulsion (Kodak), developed after $5 \mathrm{~d}$, and counterstained with cresyl violet. Neurofilament-middle (NF) antisense and BEHAB clone B1 sense probes (see Jaworski et al., 1994, for clone description) were used as positive and negative controls, respectively. 

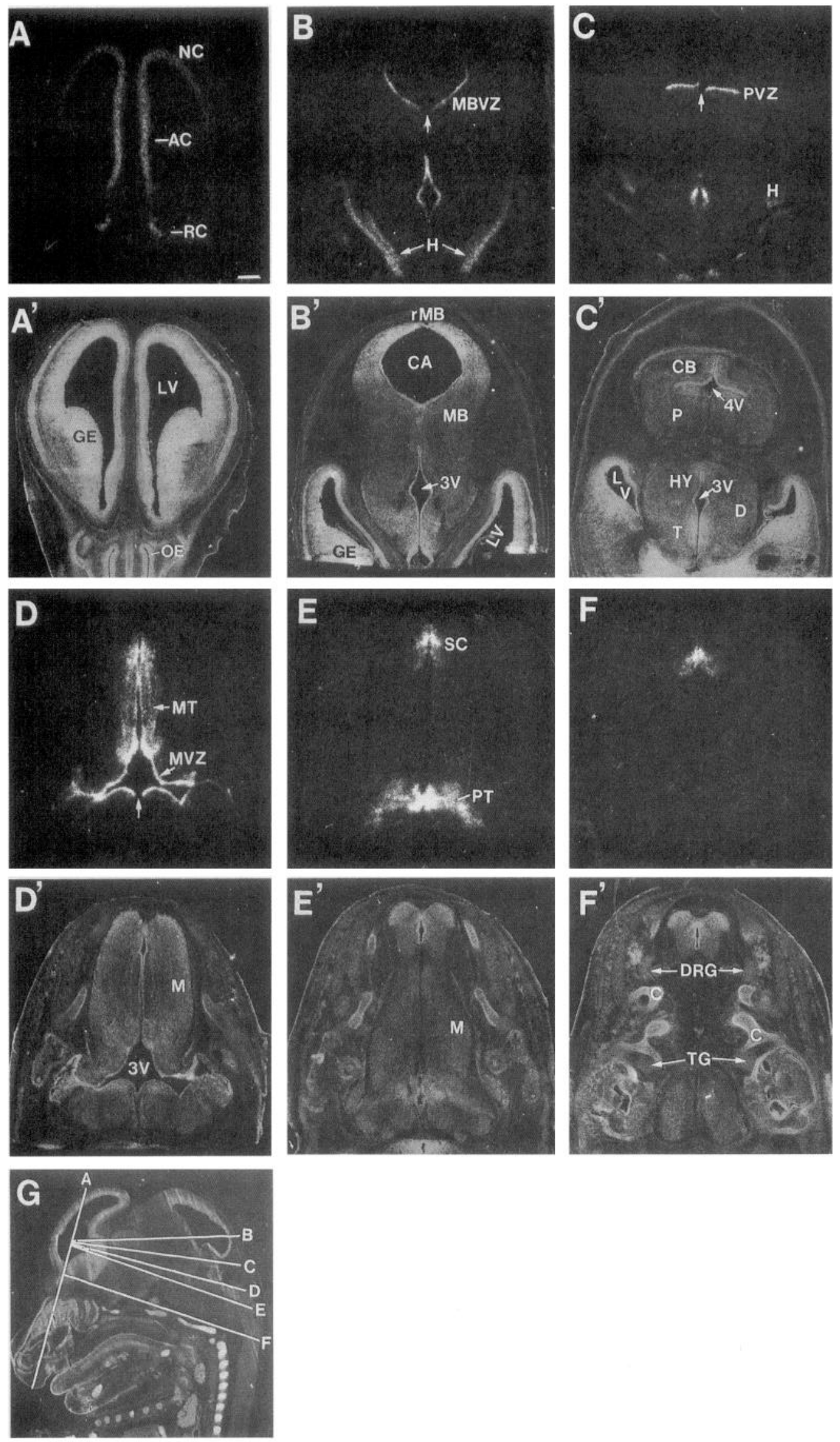


\section{Results}

\section{$B E H A B M R N A$ is restricted to the CNS and is particularly} abundant in proliferative zones

Previously, we demonstrated by Northern hybridization that BEHAB mRNA is present in the cortex and spinal cord at embryonic day 17 (E17) and that its expression is upregulated postnatally (Jaworski et al., 1994). To characterize more fully the spatial distribution and temporal regulation of BEHAB expression over the course of early brain development, in situ hybridization was performed on rats aged E14-E20 (Figs. 1-3), and P0 and P5 (Fig. 4). Sections were probed with an antisense cRNA probe of BEHAB clone $B 1$, which represents the second tandem repeat domain encoded by nucleic acids 1011-1520 (Jaworski et al., 1994). As a positive control, near-adjacent sections were probed with a cRNA probe for the middle-molecularweight subunit of neurofilament. As a negative control, sections were probed with a sense cRNA probe of clone B1, which produced virtually no detectable signal.

Over the embryonic period BEHAB expression is upregulated in the CNS. Expression is first detected at E1 5 and then increases dramatically. Consistent with previous Northern analysis of adult tissues, no BEHAB expression is detected outside of the CNS at any embryonic age. Even tissues that express high levels of $\mathrm{HA}$ and $\mathrm{HA}$-binding proteins during the embryonic period, such as precartilaginous mesenchyma, do not express $\mathrm{BEHAB}$.

Within the CNS, the temporal and spatial regulation of BEHAB expression correlates with the general features of nervous system development. The expression of BEHAB in the spinal cord and brainstem precedes that in the cortex, and throughout the neuraxis the onset of expression follows a ventral-to-dorsal gradient.

At E14 (Fig. $1 A$ ), no hybridization signal for BEHAB mRNA can be detected. BEHAB expression is first observed at E15, when it is detected at a very low level over a limited portion of the spinal cord (Fig. 1B). BEHAB expression increases at E16 (Fig. $1 C$ ) and extends from the spinal cord level seen at E15 well into the brainstem. An intense hybridization signal is present in the medulla and rostral spinal cord. A weak signal is also detected along the ventral margin of the midbrain ventricular zone. The most posterior ventral portion of the developing cortex also shows faint hybridization.

By E17 (Fig. 1D), BEHAB mRNA expression has substan- tially increased, with hybridization detected throughout the entire rostrocaudal extent of the spinal cord. In both the spinal cord and medulla BEHAB hybridization extends a greater distance from the ventricle than at younger ages. In the region of the pontine flexure, BEHAB expression is intense in the pontine tegmentum and in the medullary tegmental neuroepithelium. Expression in the midbrain is greater than that seen at E16, but remains restricted to the ventral portion of the ventricular zone. At E17 BEHAB mRNA is detected in the developing cortex, particularly in the allocortex, a region that will give rise to phylogenetically primitive cortices, such as the olfactory and limbic cortex.

At E20 (Fig. $1 E$ ), BEHAB mRNA is abundant in the hippocampus and in the ventricular zone of the developing neocortex. Neocortical BEHAB expression is restricted to the ventricular zone, with little detected in the cortical plate (see also Fig. 6). At E20 a weak hybridization signal is seen for the first time in the striatum, along its border with the lateral ventricle. In the midbrain $\mathrm{BEHAB}$ expression at $\mathrm{E} 20$ is no longer restricted to the ventral portion of the ventricular zone, but now extends along the dorsal surface of the developing cerebral aqueduct. BEHAB mRNA is not detected in the cerebellar primordium, even though there is abundant cellular proliferation at this time. While an intense hybridization signal is still present in the medullary tegmental neuroepithelium, BEHAB is more widely distributed throughout the pons and medulla. Two cranial nerve nuclei, the motor trigeminal nucleus and the facial nucleus, show particularly high levels of BEHAB hybridization. In the spinal cord, like in the brainstem, BEHAB hybridization is more widespread than at E17, extending into the ventral gray and white matter. The ventral enrichment of BEHAB in the spinal cord (see also Fig. 5) is observed at all spinal levels. The distribution of neurofilament mRNA at E20 is strikingly different from that of BEHAB (Fig. 1F). While the hybridization for BEHAB is strongest in proliferative zones, neurofilament mRNA is most abundant in regions that contain postmitotic neurons. Neurofilament mRNA is detected in the cortical plate and in the roof of the midbrain, and its hybridization signal in the hippocampus is less intense than that for BEHAB. Unlike BEHAB, neurofilament expression is detected in the thalamus, cerebellar primordium, and several brainstem nuclei. In the spinal cord, neurofilament mRNA is restricted to the motor neurons of the ventral horn.

\footnotetext{
Figure 2. The expression of BEHAB at E17 is highest in the ventral aspects of proliferative zones. To examine more closely the distribution of BEHAB in the ventricular zone, in situ hybridization was performed on coronal and transverse sections of E17 embryos. Each in situ section is shown counterstained with cresyl violet (below each in situ figure, indicated by the prime). Negative images of the cresyl violet photomicrographs were prepared by projection printing directly to photographic film. Therefore, regions of highest cell density in cresyl violet-stained sections appear white. $A / A^{\prime}$, In the forebrain, BEHAB is expressed throughout the cortical ventricular zone. The most intense hybridization is present in the archicortex $(A C)$ along the medial wall of the lateral ventricle $(L V)$. The signal in the neocortex $(N C)$ diminishes ventrolaterally and is absent from the ganglionic eminence $(G E)$. BEHAB is expressed in the rhinal cortex $(R C)$ but not the olfactory epithelium $(O E)$. B/B', The most cell-dense area of the midbrain $(M B)$ is along the roof of the midbrain $(r M B)$ overlying the cerebral aqueduct $(C A)$. In the midbrain BEHAB is restricted to the ventral aspect of the midbrain ventricular zone $(M B V Z)$ but is absent at the midline (arrow). BEHAB expression is also enriched along the ventral borders of the third ventricle $(3 V)$. Hybridization in the developing hippocampus $(H)$ is detected at several levels (panels $C$ and $D$ ). $C / C^{\prime}$, In the pons $(P), \mathrm{BEHAB}$ is restricted to the ventral aspect of the pontine ventricular zone $(P V Z)$ of the fourth ventricle (4V), and like the MBVZ is absent from the midline (arrow). BEHAB is not expressed in the cerebellar primordium $(C B)$, diencephalon $(D)$, hypothalamus $(H Y)$, or thalamus $(T)$. $D / D^{\prime}$, In the medulla $(M)$ BEHAB is enriched in the medullary ventricular zone $(M V Z)$ and more diffuse in the medullary tegmentum $(M T)$. Like the MBVZ and PVZ, BEHAB expression is excluded from the midline of the MVZ (arrow). E/E', Intense BEHAB hybridization is present in the pontine tegmentum ( $P T)$. The ventral enrichment of BEHAB is present throughout the rostrocaudal extent of the spinal cord ( $S C$ ) (panels $E$ and $F$ ). $F / F^{\prime}$, The CNS specificity of BEHAB is demonstrated by the lack of hybridization in the dorsal root ganglia $(D R G)$ and trigeminal ganglia $(T G)$. The specificity of the probe is demonstrated by the fact that BEHAB has substantial homology to aggrecan, which is expressed abundantly in cartilaginous tissues, yet no BEHAB signal is detected in cartilage $(C)$. $G$. The plane of section for each figure is indicated on this cresyl violet-stained, parasagittal section. Scale bar, $500 \mu \mathrm{m}$.
} 

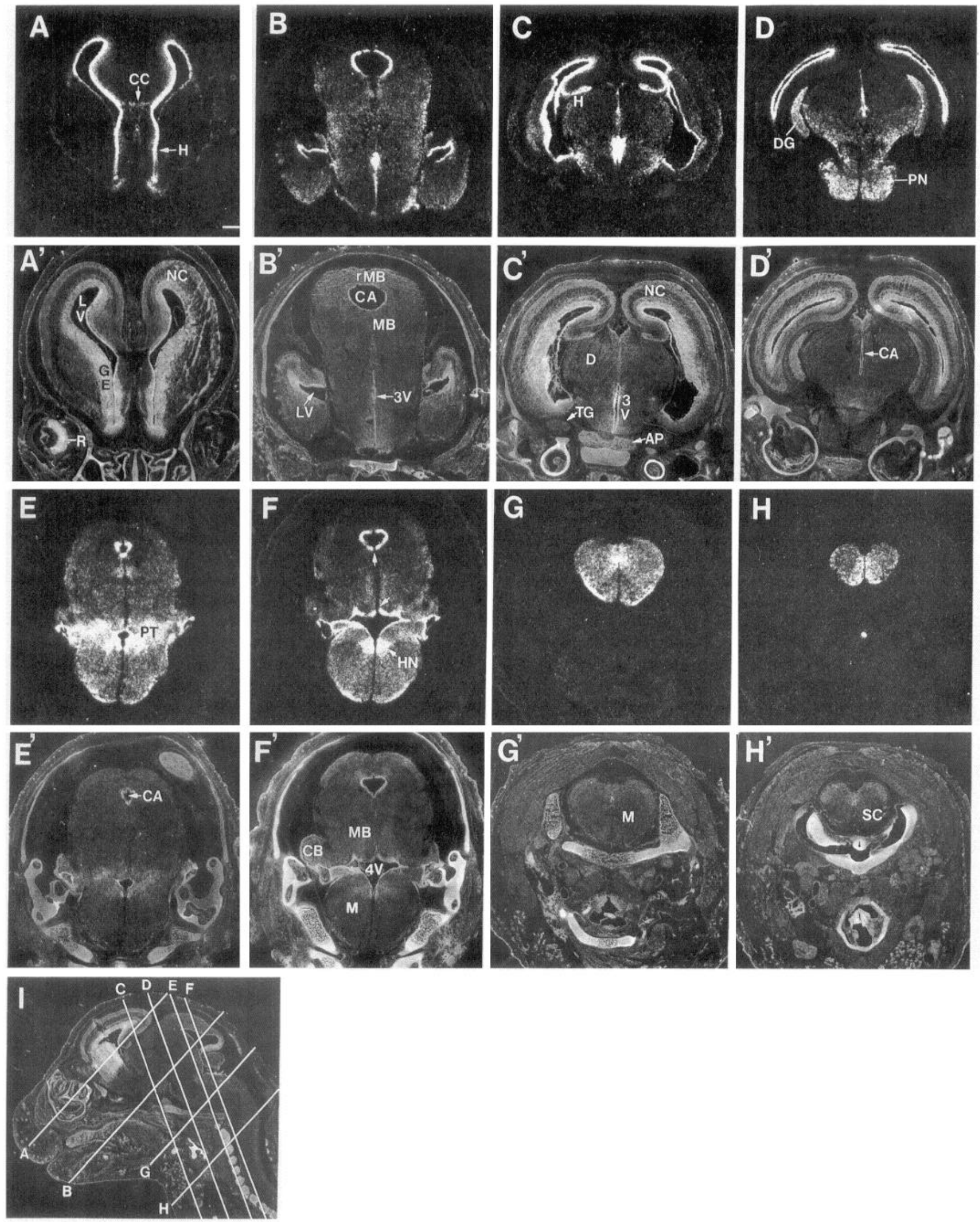


\section{At E17 BEHAB MRNA is enriched in the ventral aspects of proliferative zones}

To document more precisely the distribution of BEHAB mRNA, in situ hybridization was performed on coronal and transverse sections of E17 cmbryos (Fig. 2). The plane of section for each figure is indicated on a cresyl violet-stained sagittal section (Fig. $2 G$ ). Each section used for the in situ analysis was subsequently counterstained with cresyl violet to reveal histological details (shown below each in situ figure and indicated by a prime). Both the in situ autoradiograms and the cresyl violet-stained sections were projection printed directly to photographic film. Therefore, the cresyl violet-stained sections appear as negative images.

In sections through the forebrain of an E17 animal (Fig. 2A), BEHAB mRNA is most abundant in the ventricular zone of the developing cortex. The highest signal is present along the medial wall of the cortex, the archicortex, which will give rise to the limbic cortex. While the rhinal cortex expresses BEHAB, the olfactory epithelium shows no BEHAB hybridization. The BE$\mathrm{HAB}$ hybridization signal in the ventricular zone of the developing neocortex diminishes ventrolaterally and is absent from the ganglionic eminence.

Hybridization is clearly detected in the developing hippocampus (Fig. $2 B$ ) but, again, not in the ganglionic eminence. Signal in the underlying diencephalon is restricted to a zone immediately adjacent to the third ventricle. The dorsal borders of the third ventricle do not show any signal, while signal along the ventral borders is particularly intense. Similarly, in the midbrain, BEHAB expression is restricted to the ventral aspects of the midbrain ventricular zone. However, the midline portion of the ventricular zone does not show hybridization for BEHAB.

The restriction of BEHAB to the ventral portion of ventricular zones is dramatically illustrated in the pons (Fig. $2 C$ ), where the pontine ventricular zone of the fourth ventricle shows intense labeling over the ventral, but not the dorsal, surface. Here, again, labeling is excluded from the ventral midline. In the portion of this section that includes the diencephalon, the restriction of $B E H \wedge B$ expression to the more ventral aspects of the third ventricle can also be appreciated. At this age (E17) BEHAB is not expressed in the developing cerebellum, the thalamus, or the hypothalamus.

In the medulla (Fig. 2D), BEHAB expression is enriched in the medullary ventricular zone and is more diffuse in the medullary tegmentum. As seen in more rostral sections, along the ventricular zone of the third ventricle BEHAB expression is excluded from the ventral midline of the medulla. Intense BEHAB hybridization is present in the pontine tegmentum (Fig. $2 E$ ). Hybridization is also observed in the most rostral segments of the cervical spinal cord.

In sections through more caudal levels of the cervical spinal cord (Fig. $2 F$ ), the enrichment of BEHAB expression along the ventral aspect of the ependymal layer can be more easily appreciated. Signal also extends from the ependymal layer into the medial aspect of the ventral horn. The absence of BEHAB mRNA in dorsal root ganglia and trigeminal ganglia illustrates its CNS specificity. In addition, even though BEHAB is homologous to aggrecan, which is expressed abundantly in cartilaginous tissues, BEHAB hybridization is not detected in cartilage.

\section{At E20 BEHAB mRNA extends into the dorsal regions of ventricular zones}

The restriction of BEHAB mRNA to ventral proliferative zones at E17 is not maintained throughout development. As development proceeds, dorsal aspects of periventricular regions begin to express BEHAB. At E20, BEHAB expression is still highest in proliferative zones, but in several areas expression is no longer restricted to ventral regions (Fig. 3).

Sections through the forebrain (Fig. $3 A$ ) show that, unlike at E17, at E20 BEHAB hybridization is present throughout the entire mediolateral aspect of the neocortical ventricular zone; however, the overall medial-to-lateral gradient of expression observed at E17 is maintained. While hybridization is now detected in the ganglionic eminence, it is at a fairly low level relative to that in the cortex. A distinct but low hybridization signal is observed in the rostral portion of the corpus callosum. The retina expresses no detectable BEHAB mRNA at this age.

In the E20 hippocampus (Fig. $3 B$ ) BEHAB expression has increased from $E 17$. At this age $B E H A B$ expression is no longer restricted to the ventral aspects of the midbrain ventricular zone, but now extends to the roof of the midbrain. However, as at E17, no signal is detected at the ventral midline. The dorsal midline also shows no signal. In contrast, in the region surrounding the third ventricle, there remains a ventral enrichment of BEHAB expression.

Very high levels of BEHAB mRNA are detected in the hippocampus and neocortical ventricular zone (Fig. $3 C$ ). A rather diffuse signal can be appreciated in the diencephalon. BEHAB hybridization is not present in the trigeminal ganglia or anterior pituitary.

The presence of BEHAB mRNA throughout the neocortical

\footnotetext{
Figure 3. At E20 BEHAB expression extends into the dorsal aspects of proliferative zones. As in Figure 2, each in situ section is shown below counterstained with cresyl violet. $A / A^{\prime}$, In contrast to E17, at E20 BEHAB is expressed throughout the mediolateral extent of the neocortical ventricular zone $(N C)$, but maintains the medial-to-lateral gradient present at E17. For the first time a faint BEHAB signal is detected in the ganglionic eminence $(G E)$ along the surface of the lateral ventricle $(L V)$. The rostral portion of the corpus callosum $(C C)$ also displays a distinct yet weak hybridization signal. An intense signal is present in the hippocampus $(H)$. The retina $(R)$, which contains both neurons and glia at this age, does not express BEHAB. $B / B^{\prime}$, In the midbrain $(M B)$ BEHAB hybridization now extends around the cerebral aqueduct $(C A)$ to the roof of the midbrain $(r M B)$, and like at E17 is excluded from the midline. In the diencephalon, the ventral enrichment of signal surrounding the third ventricle ( $3 \mathrm{~V}$ ) seen at $\mathrm{E} 17$ is maintained at $\mathrm{E} 20$ (also panel $C$ ). $C / C^{\prime}, \mathrm{BEHAB}$ expression is intense in the hippocampus and neocortical ventricular zone, diffuse in the diencephalon $(D)$, and absent from the trigeminal ganglia $(T G)$ and anterior pituitary $(A P)$. $D / D$, The presence of $B E H A B$ mRNA in both the dorsal and ventral aspects of the telencephalic ventricular zone can be appreciated in this section. A high level of BEHAB expression is detected in the dentate gyrus $(D G)$. In the pons BEHAB is expressed in the pontine nucleus $(P N) . E / E^{\prime}, \mathrm{BEHAB}$ is also expressed in the pontine tegmentum $(P T) . F / F^{\prime}$, Hybridization is diffuse throughout the medulla $(M)$ and pons, except along the ventricular surface of the fourth ventricle ( $4 \mathrm{~V})$, which displays an intense signal. The hypoglossal nucleus $(I I N)$ has a high level of BEHAB expression. As demonstrated at E17 and in several planes of section, BEHAB is excluded from the midline ventricular surface of the cerebral aqueduct and fourth ventricle (arrows). Like E17 BEHAB is not expressed in the developing cerebellum $(C B)$. $G / G^{\prime}$ and $H / H^{\prime}$, In the caudal medulla $\left(G / G^{\prime}\right)$ and rostral spinal cord $(H /$ $H^{\prime}$ ) BEHAB expression is enriched in the medial and medial ventral regions. $I$, A parasagittal section indicates the plane of section for each of the sections illustrated. Scale bar, $500 \mu \mathrm{m}$.
} 


\section{BEHAB}
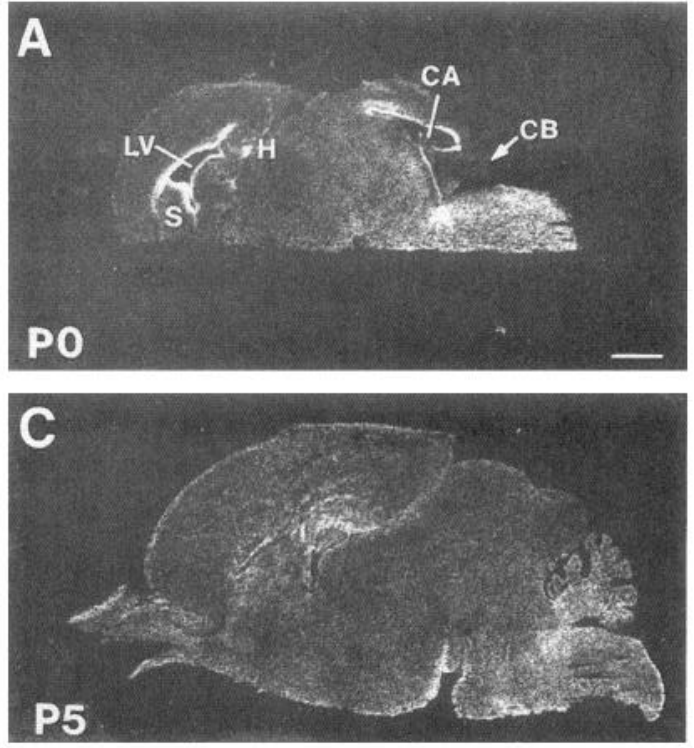

NF
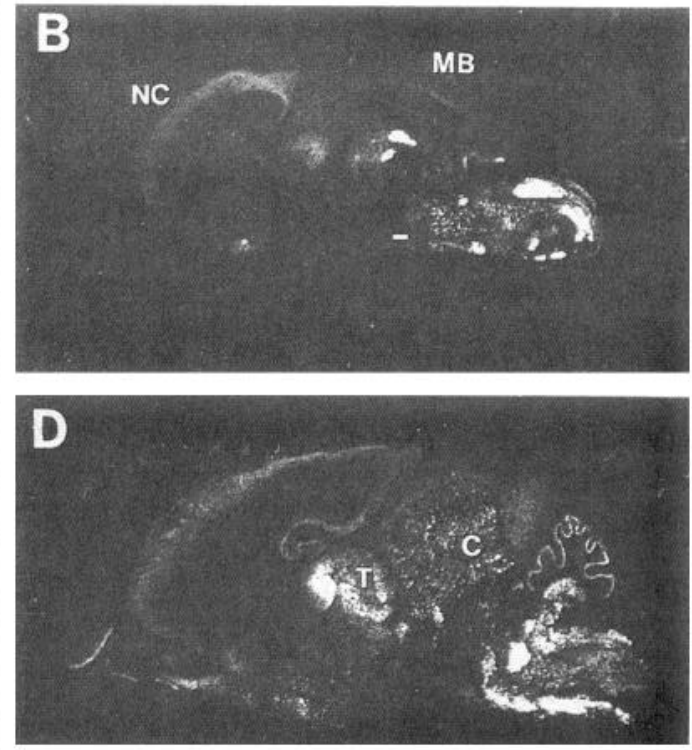

Figure 4. Sagittal sections of forebrain, cerebellum, and brainstem show that BEHAB expression in the ventricular zone decreases postnatally. Near-adjacent sections were probed with an antisense cRNA probe for BEHAB and neurofilament-middle $(N F)$. $A$, At P0 BEHAB remains enriched in the ventricular zones adjacent to the lateral ventricle $(L V)$ and cerebral aqueduct $(C A)$. BEHAB expression along the ventricular surface of the striatum $(S)$ has increased from E20. A diffuse BEHAB hybridization signal is present in the brainstem, while no signal is detected in the cerebellum $(C B)$. B. Unlike BEHAB, NF is not restricted to the ventricular zones. An NF signal is present in the parenchyma of the neocortex $(N C)$ and midbrain $(M B)$. $C$, At P5 BEHAB expression becomes more diffusely distributed in the forebrain and brainstem. In the cerebellum BEHAB appears enriched along the ventricular border but is also present in the developing cerebellar cortex. $D$, NF expression is enriched in the thalamus $(T)$ and colliculi $(C)$. In the cerebellum NF is present in the cerebellar nuclei and Purkinje cells. Scale bar, $1 \mathrm{~mm}$.

ventricular zone is clearly demonstrated in Figure $3 D$. BEHAB hybridization marks the dentate gyrus as one of the few telencephalic regions with labeling in the parenchyma at this age.

In the pons (Fig. $3 D, E$ ), BEHAB expression is enriched in the pontine nucleus (Fig. $3 D$ ) and pontine tegmentum (Fig. $3 E$ ). A somewhat lower level of expression is present in most parts of the medulla (Fig. $3 F, G$ ). As seen at both E17 and E20, and in several planes of section, BEHAB expression is absent from the midline of the ventricular zone of the cerebral aqueduct and fourth ventricle (Fig. $3 F$ ). In the medulla, the hypoglossal nucleus expresses high levels of BEHAB (Fig. $3 F$ ). As seen at E17, $\mathrm{BEHAB}$ is not expressed in the cerebellum at E20. In both the caudal medulla (Fig. $3 G$ ) and rostral spinal cord (Fig. $3 H$ ) BE$\mathrm{HAB}$ hybridization is most intense in medial and medial ventral regions.

\section{$B E H A B$ continues to be expressed in the proliferative zones as late as $\mathrm{PO}$}

To determine whether BEHAB expression in the ventricular zone is temporally restricted, in situ hybridization was performed on sagittal sections at P0 and P5 (Fig. 4). As a positive control, near-adjacent sections were hybridized with a probe for neurofilament (NF).

The pattern of $\mathrm{BEHAB}$ expression at $\mathrm{P} 0$ is very similar to that at E20. Expression is most intense along the ventricular surfaces of the cerebral cortex, striatum, and midbrain (Fig. 4A). Hybridization is also present in the hippocampus, the roof of the midbrain, and throughout the medulla and pons. BEHAB is not detected in the external granule cell layer of the cerebellum, which is undergoing granule cell proliferation at this age. $\mathrm{NF}$ is expressed at only very low levels in the cerebellum (Fig. $4 B$ ). As seen in the embryo, NF is most highly expressed in regions that contain postmitotic neurons, such as brainstem and thalamic nuclei and the deep layers of the neocortex.

At P5 (Fig. 4C), BEHAB hybridization is markedly less intense around the cerebral ventricles and has become more diffuse throughout the brain parenchyma. BEHAB mRNA is detected along the pial surface, suggesting expression by subpial astrocytes, giving the first indication that $\mathrm{BEHAB}$ is expressed by mature glial cells. BEHAB hybridization in the cerebellum is first detected at P5, when it is seen in the ventricular proliferative zone, the germinal zone for interneurons, Purkinje cells, and most glia, as well as in the developing cerebellar cortex. Unlike the diffuse pattern of BEHAB hybridization present throughout the brain, NF is expressed primarily in the thalamus, colliculi, and several brainstem nuclei (Fig. 4D). NF expression is also present in the cerebral cortex and hippocampus.

\section{In the developing spinal cord neurogenesis precedes $B E H A B$ expression}

The progression of BEHAB expression in the developing spinal cord was examined at E17 and E20 on emulsion-coated sections counterstained with cresyl violet. In the spinal cord, neurogenesis occurs between E11 and E16, with ventral motor neurons generated from E11 to E13 and dorsal horn neurons from E14 to E16 (Nornes and Das, 1974). BEHAB is first detected in only a limited portion of the spinal cord at E15 and extends rostrally into the brainstem at E16. BEHAB is not detected over the entire rostrocaudal extent of the spinal cord until E17.

At $\mathrm{E} 17$ (Fig. 5A), BEHAB expression is most intense in a dorsoventrally restricted portion of the ependymal zone surrounding the central canal. Hybridization is essentially absent from the most dorsal regions of the ependymal zone, is highest in the intermediate regions, and is present at a low level in the 
ventral most regions. Hybridization is also absent from the ventral midline. A low level of hybridization is detected radiating out from the region of most intense labeling. This band of hybridization extends into the medial portion of the ventral and intermediate horns. Even though the dorsal horn (like the ventral horn at this age) contains postmitotic, differentiated neurons, no signal is detected in the dorsal horn at E17.

One major difference between the spinal cord at E20 (Fig. 5B) compared to E17 is that at the later age BEHAB is expressed in both the dorsal and ventral horns. Hybridization signal is also detected in the white matter.

\section{In the developing cortex $B E H A B$ expression is enriched in the ventricular zone}

$\mathrm{BEHAB}$ expression in the developing cortex was more closely examined at E17, E20, and P0 on emulsion-coated sections counterstained with cresyl violet. From autoradiograms it appeared that BEHAB expression was enriched in the cortical ventricular zone (e.g., see Figs. $2 A, 3 A-D, 4 A$ ). Examination at higher magnification demonstrates that BEHAB expression is, indeed, highest in the ventricular zone. At E17 (Fig. 6A), BE$\mathrm{HAB}$ hybridization is evenly distributed throughout the ventricular zone. No hybridization signal, above the background seen in the ventricle, is present outside of the ventricular zone. At E20 (Fig. 6B), BEHAB expression remains enriched in the ventricular zone; however, unlike E17, a low level of BEHAB hybridization is detected outside the ventricular zone. By P0 (Fig. 6C), BEHAB expression in the cortex has increased considerably. Although neurogenesis is largely completed by $\mathrm{P} 0$, $\mathrm{BEHAB}$ is still most abundant in the ventricular zone.

\section{Discussion}

Previously we reported the cloning and initial characterization of BEHAB, the gene for a secreted, CNS-specific, HA-binding protein (Jaworski et al., 1994). Here we show that over the course of late embryonic and early postnatal development BE$\mathrm{HAB}$ expression is highest in the ventricular zone at all levels of the neuraxis. BEHAB is first detected in the spinal cord at embryonic day 15 (E15), in the caudal brainstem at E16 and in the cerebral cortex at E17. The highest levels of BEHAB expression are found in the ventricular zone, where it is expressed as late as postnatal day 0 (P0). By P5, BEHAB becomes more diffusely distributed in both gray and white matter. While BE$\mathrm{HAB}$ expression is not restricted to areas of cellular proliferation, several features of the early expression of BEHAB correlate with the generation of glial cells. The restriction of BEHAB to the CNS, together with its enrichment in the ventricular zone late in development, suggests a role in cell-cell and cell-matrix interactions in glial cell differentiation.

\section{The timing of BEHAB expression in proliferative zones parallels the time course of gliogenesis}

The temporal and spatial patterns of BEHAB expression parallel those of the generation of glial cells. All classes of differentiated neurons and glial cells of the adult mammalian CNS are generated from progenitor cells in the neuroepithelial layer of the neural tube. However, neurons and glia are generated in temporally distinct phases, such that (with the exception of the radial glial cells) neurons are generated before most glial cells. In the cerebral cortex, neurogenesis begins at E12 with the generation of Cajal-Retzius cells, peaks at E17, and is largely complete by birth (Bayer and Altman, 1991). Gliogenesis does not begin until
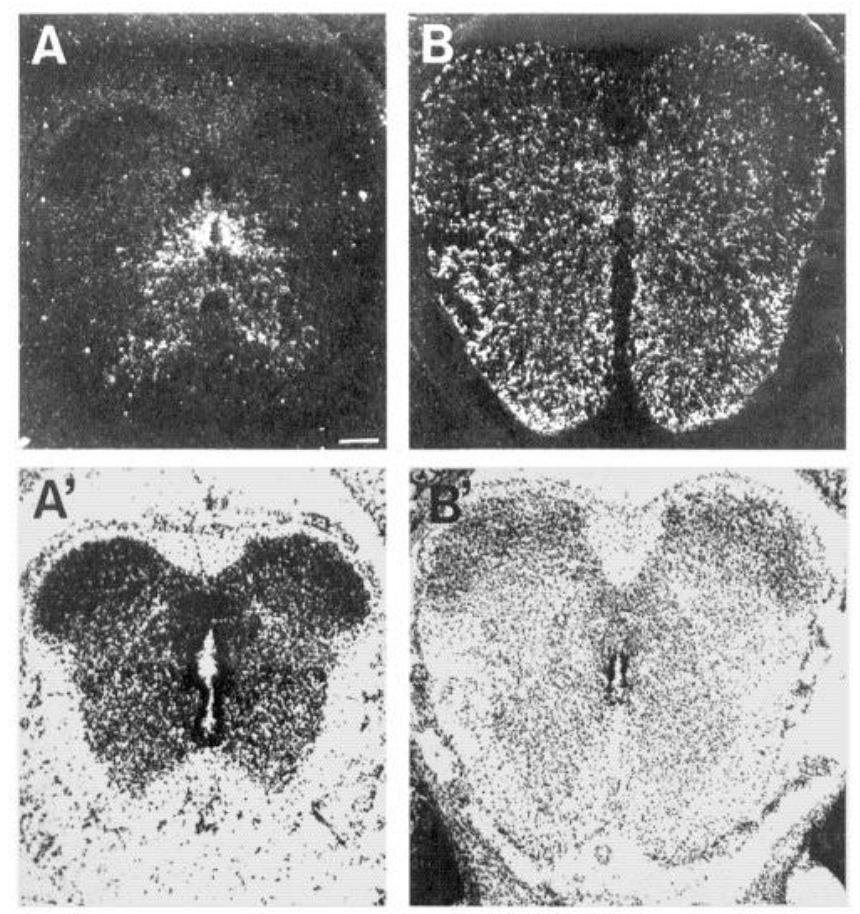

Figure 5. BEHAB mRNA is enriched in the ventral portion of the developing spinal cord. The spatial distribution of BEHAB in the spinal cord was more closely examined on emulsion-coated sections counterstained with cresyl violet (indicated by the prime). $A / A^{\prime}$, At E17, $\mathrm{BEHAB}$ hybridization is most intense in the middle portion of the ependyma surrounding the central canal. A more diffuse signal extends into the ventral and intermediate horns, while no signal is detected in the dorsal horn. $B / B^{\prime}$, By E20 BEHAB is expressed throughout the dorsal and ventral gray matter. BEHAB is also expressed in the white matter, particularly in the more ventral regions. Scale bar, $150 \mu \mathrm{m}$.

E17 and is not complete until after birth (Altman, 1966; Das, 1979). BEHAB is first detected in the cerebral cortex at E17, and the highest levels of expression in the ventricular zone are observed at E20 and P0. In the caudal brainstem gliogenesis also lags behind neurogenesis, with the first neurons generated at E11 (Altman and Bayer, 1980a-c) and the first glial cells at E16 (Das, 1979). BEHAB expression in the caudal brainstem is first detected at E16. In all the areas we have examined, BEHAB expression is highest in the ventricular zone at times after the peak of neurogenesis and coincident with the period of gliogenesis.

Like neurogenesis, gliogenesis follows both caudal-to-rostral and ventral-to-dorsal developmental gradients (Sturrock, 1982). A caudal-to-rostral gradient of BEHAB expression begins with very low levels in the spinal cord at E15, and then signal is detected at progressively more rostral levels of the neuraxis: in the medulla and caudal pons at E16, and in the midbrain and cortex at E17. A ventral-to-dorsal gradient of BEHAB expression is clearly seen in the brainstem, where it is first detected in the ventral regions of the ventricular zone at E16 and E17 and is not detected in the dorsal regions until E20.

The enrichment of BEHAB in the ventricular zone, along with its time course of expression, suggests that BEHAB is expressed by progenitor cells that are producing glia. Whether glia and neurons arise from separate populations of progenitor cells is not yet known. Retroviral studies of cell lineage indicate that in some areas of the CNS glial and neuronal progenitors diverge 

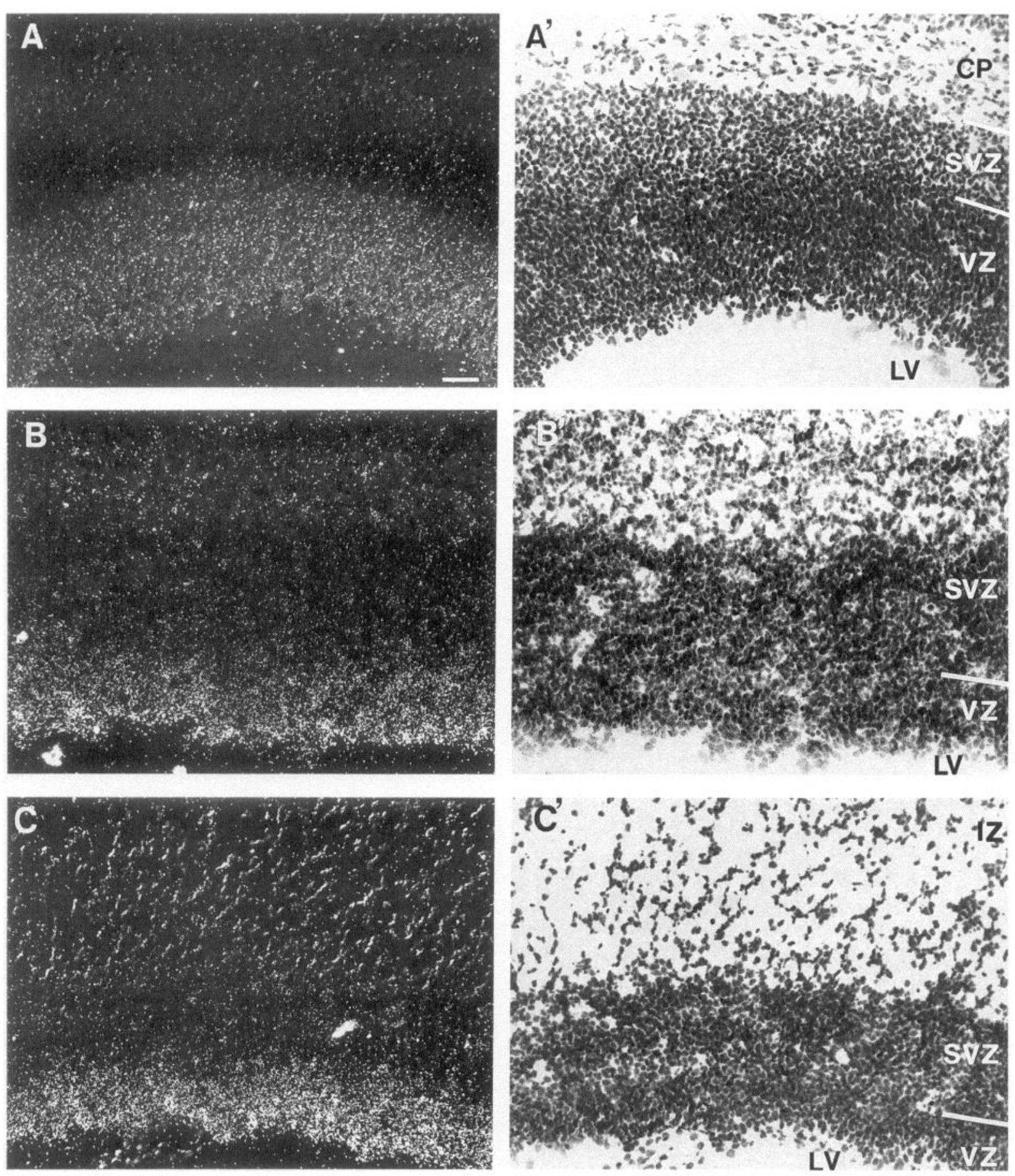

Figure 6. BEHAB mRNA is enriched in the ventricular zone of the developing cortex. The spatial distribution of BEHAB in the cortex was more closely examined on emulsion-coated sections counterstained with cresyl violet (indicate by the prime). Laminar assignments are according to Kageyama and Robertson (1993). $A / A^{\prime}$, At E17 BEHAB is only expressed in the ventricular zone of the archicortex $(V Z)$. No hybridization signal, above the background seen in the lateral ventricle $(L V)$, is detected in either the subventricular zone $(S V Z)$ or cortical plate $(C P)$. B/B', At E20 the most intense BEHAB signal is present in the neocortical ventricular zone, while a diffuse hybridization signal is now detected within the cortical parenchyma. $C / C^{\prime}$, By P0 neurogenesis is largely complete, yet BEHAB expression in the ventricular zone is quite intense. Scale bar, $50 \mu \mathrm{m}$.

before most neurons have been generated (Luskin et al., 1988, 1993). In other areas of the CNS a single progenitor cell can give rise to both neurons and glia (Turner and Cepko, 1987; Temple, 1989; Galileo et al., 1990; Leber et al., 1990; Williams et al., 1991). However, whether or not separate neuronal and glial precursors exist, it is clear from a number of different studies that neurons and glia are generated with different time courses: the peak of neurogenesis precedes the peak of gliogenesis in all areas of the CNS (Berry and Rogers, 1965; Nornes and Das, 1974; Das, 1979). Because BEHAB is expressed relatively late in embryonic development, expression cannot signal an early choice of a progenitor cell to generate glia. Rather, BEHAB expression coincides with the actual birth of cells that will become, or can generate, glial cells. 


\section{$B E H A B$ is expressed by glial precursors}

In addition to the spatial and temporal features of $\mathrm{BEHAB}$ expression, four other observations suggest that BEHAB is expressed by cells that will generate glial cells. First, the spinal cord contains a population of proliferating glial precursors in the ventral portion of the ventricular zone between E16.5 and E18.5 (Noll and Miller, 1993), in the same region and at the same developmental period we observe high levels of $B E H A B$ expression. Second, a significant upregulation of BEHAB expression occurs during reactive gliosis coincident with the expression of the PCNA (proliferating cell nuclear antigen), a marker for mitotic cells (D. M. Jaworski, G. M. Kelly, and S. Hockfield, unpublished observations). Third, human glioblastoma shows an exceptionally high level of BEHAB (D. M. Jaworski and S. Hockfield, unpublished observations). Fourth, the distribution of BEHAB in the mature CNS is consistent with expression by astrocytes (Jaworski et al., 1994). Together these observations indicate that BEHAB is expressed by cells that can give birth to glia.

\section{$B E H A B$ expression in the ventricular zone suggests $a$ participation in $\mathrm{HA}$-mediated cellular interactions}

The high level of expression of BEHAB in the ventricular zone is consistent with a role in regulating cellular differentiation. In non-neural tissues, elements of the extracellular matrix control both the rate of cell division and the state of ccll differentiation. In the CNS, the commitment to some features of cellular phenotype occurs concurrent with the last cell division, just prior to the time when a cell leaves the ventricular zone (Levitt et al., 1981; McConnell and Kaznowski, 1991). Cell fate choice may be influenced by the expression of temporally regulated environmental cues within the ventricular zone (McConnell, 1989). Since BEHAB expression is enriched in the ventricular zone, it could provide a differentiation signal, either to stimulate the generation of glia or to inhibit the production of neurons, along the lines suggested in previous studies (Gao et al., 1991; McConnell, 1992; Reh, 1992; Shah et al., 1994).

Hyaluronan and HA-binding proteins have been shown to play a role in regulating cellular proliferation in non-neural tissues. HA and CD44 (an HA-binding protein) are enriched in (but not restricted to) proliferative zones in the skin (Alho and Underhill, 1989; Tammi ct al., 1989). In addition, HA can stimulate cell proliferation (Brecht et al., 1986; Toole, 1991). In the CNS, HA concentrations are highest during the embryonic period (Margolis et al., 1975; Delpech et al., 1989). Like embryonic extracellular matrices, tumor-associated stroma are enriched in $\mathrm{HA}$, where $\mathrm{HA}$ is thought to facilitate both proliferation and tumor invasion (Knudson et al., 1989; Knudson and Knudson, 1993). The HA-binding protein encoded by BE$\mathrm{HAB}$ is expressed at very high levels in areas of mitotic activity. By binding $\mathrm{HA}, \mathrm{BEHAB}$ could help sequester $\mathrm{HA}$ in these areas. The observed upregulation of BEHAB in glioblastoma is consistent with a facilitory role in mitotic activity. Further evidence for extracellular matrix proteins regulating neural cell proliferation comes from Drosophila, where a glycoprotein secreted by glia negatively regulates neuroblast proliferation (Ebens et al., 1993).

Extracellular matrix molecules also have been shown to be required for cellular differentiation in a number of systems (reviewed in Adams and Watt, 1993; Jones et al., 1993; Lin and Bissell, 1993). For example, extracellular matrix is required for cultured hepatocytes to acquire a differentiated morphology as well as to express albumin and two liver-specific transcription factors (Caron, 1990; Dipersio et al., 1991). Similarly, mammary epithelial cells require extracellular matrix elements to attain a mature morphology and to express the full repertoire of milk proteins (Lee et al., 1984; Chen and Bissell, 1989). In Drosophila, cell fate is regulated by the extracellular domain of several transmembrane molecules (reviewed by Banerjee and Lipursky, 1990; Campos-Ortega, 1993), including notch (Lieber et al., 1992; Coffman et al., 1993; Heitzler and Simpson, 1993) and sevenless (Rubin, 1991; Zipursky et al., 1992). In the mammalian CNS, the differentiation of type 2 astrocytes requires extracellular matrix-associated molecules made by nonglial cells in addition to ciliary neurotrophic factor made by type 1 astrocytes (Lillien et al., 1990). Cerebellar granule cell fate is also regulated by the expression of cell surface molecules (Gao et al., 1991). BEHAB, a secreted protein with both HA-binding and immunoglobulin-like domains, is a good candidate for playing a role in matrix-mediated differentiation.

Although $\mathrm{HA}$ is a ubiquitous component of the extracellular matrix of virtually all tissues, BEHAB represents the only CNSspecific $\mathrm{HA}$-binding protein reported to date. $\mathrm{BEHAB}$ is a highly conserved (Jaworski et al., 1994), developmentally regulated protein restricted to the CNS. Its structure and expression in ventricular zones concurrent with the generation of glia suggest that BEHAB is an important component of the CNS extracellular matrix that may have a role in proliferation or cell fate decisions during neural development.

\section{References}

Adams JC, Watt FM (1993) Regulation of development and differentiation by the extracellular matrix. Development 117:1183-1198.

Alho AM, Underhill CB (1989) The hyaluronate receptor is preferentially expressed on proliferating epithelial cells. J Cell Biol 108: $1557-1565$.

Altman J (1966) Proliferation and migration of undifferentiated precursor cells in the rat during postnatal gliogenesis. Exp Neurol 16: 263-278.

Altman J, Bayer SA (1980a) Development of the brain stem in the rat. I. Thymidine-radiographic study of the time of origin of ncurons of the lower medulla. J Comp Neurol 194:1-35.

Altman J, Bayer SA (1980b) Development of the brain stem in the rat. II. Thymidine-radiographic study of the time of origin of neurons of the upper medulla, excluding the vestibular and auditory nuclei. $\mathrm{J}$ Comp Neurol 194:37-56.

Altman J, Bayer SA (1980c) Development of the brain stem in the rat. IV. Thymidine-radiographic study of the time of origin of neurons in the pontine region. J Comp Neurol 194:905-929.

Banerjee U, Zipursky SL (1990) The role of cell-cell interaction in the development of the Drosophila visual system. Neuron 4:177-187.

Bayer SA, Altman J (1991) Neocortical development. New York: Raven.

Berry M, Rogers AW (1965) The migration of neuroblasts in the developing cortex. J Anat 99:691-709.

Brecht M, Mayer U, Schlosser E, Prehm P (1986) Increased hyaluronate synthesis is required for fibroblast detachment and mitosis. Biochem J 239:445-450.

Campos-Ortega JA (1993) Mechanisms of early neurogenesis in Drosophila melanogaster. J Neurobiol 24:1305-1327.

Caron JM (1990) Induction of albumin gene transcription in hepatocytes by extracellular matrix. Mol Cell Biol 10:1239-1243.

Chen L-H, Bissell MJ (1989) A novel regulatory mechanism for whey acidic protein gene expression. Cell Regul 1:45-54.

Coffman CR, Skoglund P, Harris WA, Kintner CR (1993) Expression of an extracellular deletion of Xotch diverts cell fate in Xenopus embryos. Cell 73:659-671.

Das GD (1979) Gliogenesis and ependymogenesis during embryonic development of the rat. J Neurol Sci 43:193-204.

Delpech B, Delpech A, Bruckner G, Girard N, Maingonnat C 
Hyaluronan and hyaluronectin in the nervous system. In: Ciba Foundation symposium 143, The biology of hyaluronan (Evered D, Whelan J, eds), pp 208-232. Chichester: Wiley.

Dipersio CM, Jackson DA, Zaret KS (1991) The extracellular matrix coordinately modulates liver transcription factors and hepatocyte morphology. Mol Cell Biol 11:4405-4414.

Ebens AI, Garren H, Cheyette BNR, Zipursky SL (1993) The Drosophila anachronism locus: a glycoprotein secreted by glia inhibits neuroblast proliferation. Cell 74:15-27.

Frank E, Sanes JR (1991) Lineage of neurons and glia in chick dorsal root ganglia: analysis in vivo with a recombinant retrovirus. Development 111:895-908.

Galileo DS, Gray GE, Owens GC, Majors J, Sanes JR (1990) Neurons and glia arise from a common progenitor in chicken optic tectum: demonstration with two retroviruses and cell type-specific antibodies. Proc Natl Acad Sci USA 87:458-462.

Gao W-Q, Heintz N, Hatten ME (1991) Cerebellar granule cell neurogenesis is regulated by cell-cell interaction. Neuron 6:705-715.

Heitzler P, Simpson P (1993) Altered epidermal growth factor-like sequences provide evidence for a role of Notch as a receptor in cell fate decisions. Development 117:1113-1123.

Jaworski DM, Kelly GM, Hockfield S (1994) BEHAB, a new member of the proteoglycan tandem repeat family of hyaluronan binding proteins that is restricted to brain. J Cell Biol 125:495-509.

Jones PL, Schmidhauser C, Bissell MJ (1993) Regulation of gene expression and cell function by extracellular matrix. Crit Rev Eukary Gene Exp 3:137-154.

Kageyama GH, Robertson RT (1993) Development of geniculocortical projections to visual cortex in rat: evidence for early ingrowth and synaptogenesis. J Comp Neurol 335:123-148.

Knudson CB, Knudson W (1993) Hyaluronan-binding proteins in development, tissue homeostasis and disease. FASEB J 7:1233-1241.

Knudson W, Biswas C, Li Q, Nemec RE, Toole BP (1989) The role and regulation of tumor-associated hyaluronan. In: Ciba Foundation symposium 143, The biology of hyaluronan (Evered D, Whelan J, eds), pp 150-169. Chichester: Wiley.

Laurent TC, Fraser JRE (1992) Hyaluronan. FASEB J 6:2397-2404.

Leber SM, Breedlove SM, Sanes JR (1990) Lineage and death of clonally related motor neurons in chick spinal cord. J Neurosci 10: 2451-2462.

Lee EY-H, Parry G, Bissell MJ (1984) Modulation of secreted proteins of mouse mammary epithelial cells by the collagenous substrata. $\mathbf{J}$ Cell Biol 98:146-155.

LeVine SM, Goldman JE (1988) Embryonic divergence of oligodendrocyte and astrocyte lineages in developing rat cerebrum. J Neurosci 8:3992-4006.

Levitt P, Cooper ML, Rakic P (1981) Coexistence of neuronal and glial precursor cells in the cerebral ventricular zone of the fetal monkey: an ultrastructural immunoperoxidase analysis. J Neurosci 1:2739.

Levitt P, Cooper M, Rakic P (1983) Early divergence and changing proportions of neuronal and glial precursor cells in the primate cerebral ventricular zone. Dev Biol 96:472-484.

Lieber T, Wesley CS, Hassel B, Krane JF, Campos-Ortega JA, Young MW (1992) Single amino acid substitutions in EGF-like elements of notch and delta modify Drosophila development and affect cell adhesion in vitro. Neuron 9:847-859.
Lillien LE, Sendtner M, Raff MC (1990) Extracellular matrix-associated molecules collaborate with ciliary neurotrophic factor to induce type-2 astrocyte development. J Cell Biol 111:635-644.

Lin CQ, Bissell MJ (1993) Multi-faceted regulation of cell differentiation by extracellular matrix. FASEB J 7:737-743.

Luskin MB, Pearlman AL, Sanes JR (1988) Cell lineage in the cerebral cortex of the mouse studied in vivo and in vitro with a recombinant retrovirus. Neuron 1:635-647.

Luskin MB, Parnevelas JG, Barfield JA (1993) Neurons, astrocytes, and oligodendrocytes of the rat cerebral cortex originate from scparatc progenitor cells: an ultrastructural analysis of clonally related cells. $J$ Neurosci 13:1730-1750.

Margolis RU, Margolis RK, Chang LB, Preti C (1975) Glycosaminoglycans of brain during development. Biochemistry 14:85-88.

McConnell SK (1989) The determination of neuronal fate in the cerebral cortex. Trends Neurosci 12:342-349.

McConnell SK (1992) The genesis of neuronal diversity during development of cerebral cortex. Semin Neurosci 4:347-356.

McConnell SK, Kaznowski CE (1991) Cell cycle dependence of laminar determination in developing neocortex. Science 254:282-285.

Noll E, Miller RH (1993) Oligodendrocyte precursors originate at the ventral ventricular zone dorsal to the ventral midline in the embryonic rat spinal cord. Development 118:563-573.

Nornes HO, Das GD (1974) Temporal pattern of neurogenesis in spinal cord of rat. I. An autoradiographic study-time and sites of origin and migration and settling patterns of neuroblasts. Brain Res 73:121-138.

Price J, Thurlow L (1988) Cell lineage in the rat cerebral cortex: a study using retroviral-mediated gene transfer. Development 104:473482.

Rakic P (1981) Neuronal-glia interaction during brain development. Trends Neurosci 4:184-187.

Reh TA (1992) Cellular interactions determine neuronal phenotypes in rodent retinal cultures. J Neurobiol 23:1067-1083.

Rubin GM (1991) Signal transduction and the fate of the R7 photoreceptor in Drosophila. Trends Genet 7:372-377.

Shah NM, Marchionni MA, Isaacs I, Stroobant P, Anderson DJ (1994) Glial growth factor restricts mammalian neural crest stem cells to a glial fate. Cell 77:349-360.

Sturrock RR (1982) Gliogenesis in the prenatal rabbit spinal cord. J Anat 134:771-793.

Tammi R, Ripellino JA, Margolis RU, Maibach HI, Tammi M (1989) Hyaluronate accumulation in human epidermis treated with retinoic acid in skin and organ culture. J Invest Dermatol 92:326-332.

Temple S (1989) Division and differentiation of isolated CNS blast cells in microculture. Nature 340:471-473.

Toole BP (1991) Proteoglycans and hyaluronan in morphogenesis and differentiation. In: Cell biology of extracellular matrix (Hay ED, ed), pp 305-341. New York: Plenum.

Turner DL, Cepko CL (1987) A common progenitor for neurons and glia persists in rat retina late in development. Nature 328:131-136.

Williams BP, Read J, Price J (1991) The generation of neurons and oligodendrocytes from a common precursor cell. Neuron 7:685-693.

Zipursky SL, Kramer H, Cagan R, Hart A, Van Vactor D Jr (1992) Induction of the R7 neuron in the Drosophila compound eye: the bride of sevenless and sevenless interaction. Cold Spring Harbor Symp Quant Biol 57:381-389. 